\title{
Evaluation of Zinc Sulfate as an Adjunctive Therapy in COVID-19 Critically III Patients: a Two Center Propensity-score Matched Study
}

Khalid Al Sulaiman ( $\square$ alsulaimankh@hotmail.com )

King Abdulaziz Medical City https://orcid.org/0000-0002-5547-2043

Ohoud Al Juhani

King Abdulaziz University

Abdulrahman I Al Shaya

King Saud bin Abdulaziz University for Health Sciences

Abdullah Kharbosh

Taif University

\section{Raed Kensara}

King Abdulaziz Medical City

Alhomaidi Al Guwairy

King Saud bin Abdulaziz University for Health Sciences

Aisha Alharbi

King Abdulaziz University Hospital

Rahmah Algarni

King Abdulaziz University Hospital

Shmeylan Al Harbi

King Saud bin Abdulaziz University for Health Sciences

Ramesh K. Vishwakarma

King Abdullah International Medical Research Center

Ghazwa B. Korayem

Princess Nourah bint Abdulrahman University

\section{Research Article}

Keywords: COVID-19, SARS-CoV-2, Zinc, Supplements, Trace element, Critically ill, Intensive Care Unit (ICU), 30-day mortality

Posted Date: June 7th, 2021

DOI: https://doi.org/10.21203/rs.3.rs-572942/v1 
License: (c) (i) This work is licensed under a Creative Commons Attribution 4.0 International License. Read Full License 


\section{Abstract}

\section{Background:}

Zinc is a trace element that plays a role in stimulating innate and acquired immunity. The role of zinc in critically ill patients with COVID-19 remains unclear. This study aims to evaluate the efficacy and safety of zinc sulfate as adjunctive therapy in critically ill patients with COVID-19.

\section{Methods:}

Patients aged $\geq 18$ years with a COVID-19 who were admitted to the intensive care unit (ICU) in two tertiary hospitals in Saudi Arabia were retrospectively assessed for zinc use, from 01 March 2020 until 31December 2020. We assessed the association of zinc use as adjunctive therapy with the in-hospital and 30-day mortality after propensity score matching. Secondary outcomes included mechanical ventilation (MV) duration, ICU length of stay (LOS), hospital LOS, and complication (s) during ICU stay.

\section{Results:}

A total of 266 patients were included in this study after using propensity score matching. Zinc sulfate as adjunctive therapy during ICU stay was not associated with statistically significant reduction in 30-day mortality nor in-hospital mortality compared to those who did not receive zinc $(\mathrm{HR}=0.65 \mathrm{Cl}=0.41,1.01$; $p=0.05$ and $\mathrm{HR}=0.67 \mathrm{Cl}=0.45,1.00 ; p=0.05$; respectively). Moreover, $\mathrm{MV}$ duration (Beta coefficient 0.10 $\mathrm{Cl}=-0.19,0.39 ; p=0.48$ ), ICU LOS (Beta coefficient $0.19 \mathrm{Cl}=-0.02,0.40 ; p=0.08$ ) and hospital LOS (Beta coefficient $0.15 \mathrm{Cl}=-0.02,0.32 ; p=0.08$ ) were not statistically significant between the two groups. Patients who received zinc have a higher odds of acute kidney injury (AKI) during ICU stay $(O R=1.80 \mathrm{Cl}=1.08-3.0$; $p=0.02)$.

\section{Conclusion:}

Zinc sulfate as adjunctive therapy in critically ill patients with COVID-19 may have survival benefit; however, was not statistically significant. Zinc use was linked with an increased risk of AKI development during ICU stay.

\section{Background}

The coronavirus disease 2019 (COVID-19), caused by the severe acute respiratory syndrome coronavirus 2 (SARS-CoV-2), has emerged as a threat to public health worldwide[1] Symptoms of COVID-19 manifest as a cluster of mild to severe respiratory symptoms [1]. Severe COVID-19 amplifies the overall systematic inflammatory response in critically ill patients, increasing the risk of multi-organ dysfunctions, including acute respiratory disease syndrome (ARDS) and mortality[1-4]. This inflammatory response is caused by the hyperactivation of chemokines and cytokines, a prominently interleukin-6 (IL-6)[3]. Therefore, the dysregulation of cytokines was one of the targets for many treatment strategies in treating patients with severe COVID-19[3]. 
To date, no specific pharmacological agents have proven efficacy against SARS-CoV-2; instead, hostdirected therapies and supportive therapy are used[5] The current treatment options for COVID-19 critically ill patients include anti-viral agents, immunosuppressive agents, and immunomodulators[6]. However, the evidence about these treatment options' mortality benefit in critical patients with COVID-19 is conflicting[7-10] Moreover, some mineral supplements and vitamins with immunomodulatory activity and antioxidant effects such as thiamine, vitamins $C$ and $D$, zinc, and selenium metals use in patients with COVID-19 are investigated[11]. [12] [13, 14]

Zinc is a trace element that plays a role in the development and function of the immune system exhibiting direct or indirect anti-viral properties [14]. [14, 15] High intracellular zinc levels were reported to stall the replication of the severe acute respiratory syndrome coronavirus (SARS-CoV) that caused the severe acute respiratory syndrome and influenza virus $[13,15,16]$. Moreover, some reports demonstrate the synergistic effect of zinc with anti-viral therapy in SARS-CoV[17]. Zinc supplementation favorable outcomes on immune system function in non-COVID-19 critically ill patients have been observed in several studies $[17,18]$. However, the data supporting zinc use for COVID-19 treatment in critically ill patients insufficient [19]. Yet, providers continue to use it as adjunctive therapy in this patient population. Therefore, we aim to evaluate the efficacy and safety of zinc supplementation in treating critically ill patients with COVID-19.

\section{Methods}

\section{Study design}

This was a two-center, retrospective study of prospectively collected data of all consecutive critically ill COVID-19 patients who were admitted to the ICU from 01 March 2020 until 31-December 2020. We aimed to enroll as many patients as possible, with no predefined sample size. COVID-19 was confirmed using a reverse transcriptase-polymerase chain reaction (RT-PCR) obtained from nasopharyngeal or throat swabs. The study was approved by King Abdullah International Medical Research Center (KAIMRC)-Institutional Review Board, Riyadh, Saudi Arabia (Study Number: RC20/589/R).

\section{Participants}

Patients aged $\geq 18$ years and were admitted to ICU for more $>24$ hours with a confirmed COVID- 19 were eligible for inclusion. Patients were excluded if were placed as "Do-Not-Resuscitate" code status within 24 hours of ICU admission. Enrolled patients were classified into two groups based on the administration of zinc sulfate use as adjunctive therapy during ICU stay. Patients who received zinc sulfate $220 \mathrm{mg}$ (50 mg of elemental zinc) enterally tablets as new initiation in the ICU or prior to ICU admission and continued during ICU stay were included in the active group. Patients were followed during their hospital stay, until discharge or in-hospital death, whichever occurred first.

\section{Setting}


This study was conducted in two large, tertiary governmental hospitals; King Abdulaziz Medical City (KAMC), Riyadh, and King Abdulaziz University Hospital (KAUH), Jeddah. The ICUs admit medical, surgical, trauma, burn, and transplant patients and operate as a closed unit with $24 / 7$ onsite coverage by critical care board-certified intensivists. The distributions of total enrolled patients were $77 \%$ and $23 \%$ in KAMC-CR and KAUH, respectively. The primary site for this study was KAMC, Riyadh.

\section{Data collection}

Patients' demographic data, comorbidities, vital signs, and laboratory tests were extracted from electronic medical records. The following labs were gathered renal profile, liver function tests (LFTs), coagulation profile (i.e., INR, aPTT, fibrinogen), inflammatory markers (C-reactive protein (CRP), procalcitonin) within 24 hours of ICU admission, and the "worst" values of inflammatory markers during ICU stay (maximum or minimum, depending on the parameter). The severity baseline scores (i.e., Acute Physiology And Chronic Health Evaluation II (APACHE II), Sequential Organ Failure Assessment (SOFA), and Nutrition Risk in Critically ill (NUTRIC)) were calculated for each patient. In addition, we collected the Glasgow Coma Score (GCS), fluid balance status, the needs for mechanical ventilation (MV), and MV parameters (e.g., $\mathrm{PaO}_{2} / \mathrm{FiO}_{2}$ ratio, $\mathrm{FiO}_{2}$ requirement) within 24 hours of ICU admission.

\section{Aim of study and Outcomes}

This study aims to evaluate the efficacy and safety of zinc sulfate as adjunctive therapy in critically ill patients with COVID-19.The primary outcomes were the 30-day and in-hospital mortality in critically ill patients who received zinc sulfate as adjunctive therapy. The secondary outcomes include ICU LOS, hospital LOS, mechanical ventilation (MV) duration, and evaluation of complications during ICU stay, including acute kidney injury (AKI), liver injury, a respiratory failure that requires $\mathrm{MV}$, and thrombosis/infraction during ICU stay.

\section{Definition (s)}

- Acute kidney injury (AKI) was defined using the Acute Kidney Injury Network (AKIN) definition [20].

- Thrombosis/infraction was defined using ICD10-CM code (i.e. Myocardial infarction (MI), ischemic stroke, pulmonary embolism, deep vein thrombosis)[21]

- Respiratory failure was defined as either hypoxemic respiratory failure $\left(\mathrm{PaO}_{2}<60 \mathrm{~mm} \mathrm{Hg}\right.$ with a normal or low arterial carbon dioxide tension $\left(\mathrm{PaCO}_{2}\right)$ or hypercapnic respiratory failure $\left(\mathrm{PaCO}_{2}>50\right.$ $\mathrm{mm} \mathrm{Hg}$ ) that requires invasive mechanical ventilation.

- Liver injury is defined as alanine aminotransferase (ALT) exceeding three times the upper limit of normal or double in patients with elevated baseline ALT.

\section{Data management and Statistical analysis}

Categorical variables were reported using numbers and percentages, whereas continuous variables reported using mean with standard deviation (SD) or median with interquartile range (IQR) when 
appropriate. We compared categorical variables using the Chi-square or Fisher exact test. Continuous variables were compared using numerical the student-t test (for the normally distributed variables) or other quantitative variables with the Mann-Whitney $\mathrm{U}$ test (for the non-normally distributed variables). The normality assumptions were assessed for all numerical variables using statistical tests (i.e., ShapiroWilk test) and graphical representation (i.e., histograms and Q-Q plots).

Propensity score matching procedure (Proc PS match) (SAS, Cary, NC) was used to match patients who received zinc sulfate (active group) to patients who did not (control group) based on baseline severity scores (i.e., APACHE II, SOFA score, NUTRIC scores), systemic use of corticosteroids and study centers. A greedy nearest neighbor matching method was used in which one patient who received zinc sulfate (active) group matched with one patient who did not (control), which eventually produced the smallest within-pair difference among all available pairs with treated patients. Patients were matched only if the difference in the logits of the propensity scores for pairs of patients from the two groups was less than or equal to 0.5 times the pooled estimate of the standard deviation.

Model fit assessed using the Hosmer-Lemeshow goodness-of-fit test. Multivariable Cox proportional hazards regression analyses were performed for the 30-day and in-hospital mortality. Additionally, Kaplan-Meier (KM) plots were generated for these outcomes. Multivariable regression analysis and negative binomial regression were used for the other outcomes considered in this study. The odds ratios (OR), hazard ratio (HR), or estimates with the $95 \%$ confidence intervals $(\mathrm{Cl})$ were reported as appropriate. No imputation was made for missing data as the cohort of patients in our study was not derived from random selection. We considered a $P$ value of $<0.05$ statistically significant and used SAS version 9.4 for all statistical analyses.

\section{Results}

A total of 738 critically ill patients with COVID-19 were admitted to the ICU during the study period in the two study centers. Zinc sulfate was administered to 140 patients, whereas 598 patients did not receive zinc as adjunctive therapy. We matched 266 patients using propensity score matching (1:1) according to the selected criteria. The active group received zinc sulfate for a median duration of 12 days (IQR 8-15). Most patients (70.3\%) received zinc early within three days of ICU admission as new initiation or initiated prior to ICU admission (e.g., wards) and continuation during ICU stay.

\section{Study population}

The majority of the patients in both arms were men (72\%), and the average age of the patients was $60 \pm$ 15 years in the whole cohort. (Additional file 1: Table e1). The most common comorbidities were diabetes mellitus (61\%), hypertension (56.8\%), and dyslipidemia (23.2\%) (Additional file 2: Table e2). Severity scores (i.e., APACHE II and SOFA scores), fibrinogen levels, AKI, and MV needs within 24 hours of ICU admission were higher in the control group. There were no significant differences in the baseline and demographic characteristics after adjusting for patients' baseline severity scores, systemic corticosteroids, and hospital centers (Additional file 1: Table e1). 


\section{Primary endpoints}

Forty-four patients (33.6\%) died during hospital stay among the zinc group, compared with 56 patients $(42.7 \%)$ in the control group. The overall survival probabilities were higher during hospital stayed among patients who received zinc before and after propensity score-matched (Fig. 1a,1b).

At multivariable Cox proportional hazards regression analyses, the 30-day and in-hospital mortality were lower in patients who received zinc sulfate $(\mathrm{HR}=0.65 \mathrm{Cl}=0.41,1.01 ; p=0.05$ and $\mathrm{HR}=0.67 \mathrm{Cl}=0.45,1.00$; $p=0.05$; respectively); however, it was not statistically significant (Table 1$)$.

Table 1

Regression analysis for the outcomes

\begin{tabular}{|c|c|c|c|c|c|}
\hline \multirow[t]{2}{*}{ Outcomes } & \multicolumn{3}{|c|}{ Crude analysis } & \multirow{2}{*}{$\begin{array}{l}\text { Hazard Ratio (HR) } \\
(95 \% \mathrm{Cl})\end{array}$} & \multirow{2}{*}{$\begin{array}{l}p \\
\text { value }\end{array}$} \\
\hline & Control & Zinc & $\begin{array}{l}\mathrm{P}- \\
\text { value }\end{array}$ & & \\
\hline In-hospital mortality, n(\%) & $\begin{array}{l}56 / 131 \\
(42.7)\end{array}$ & $\begin{array}{l}44 / 131 \\
(33.6)\end{array}$ & $0.13^{\wedge \wedge}$ & $0.67(0.45,1.00)$ & $0.05 \$$ \\
\hline \multirow[t]{2}{*}{ 30-day mortality, $n(\%)$} & $\begin{array}{l}45 / 129 \\
(34.9)\end{array}$ & $\begin{array}{l}35 / 130 \\
(26.9)\end{array}$ & $0.17^{\wedge \wedge}$ & $0.65(0.41,1.01)$ & $0.05 \$$ \\
\hline & & & & $\begin{array}{l}\text { beta coefficient } \\
\text { (Estimates) }(95 \% \mathrm{Cl})\end{array}$ & $\begin{array}{l}\mathrm{p} \\
\text { value }\end{array}$ \\
\hline $\begin{array}{l}\text { MV duration during ICU } \\
\text { (Days), Median (IQR) \&\# }\end{array}$ & $\begin{array}{l}9.0(4.0 \\
15.0)\end{array}$ & $\begin{array}{l}11.0 \\
(3.50 \\
19.0)\end{array}$ & $0.60^{\wedge}$ & $0.10(-0.19,0.39)$ & $\begin{array}{l}0.48 \\
\$^{*}\end{array}$ \\
\hline $\begin{array}{l}\text { ICU Length of Stay (Days), } \\
\text { Median (IQR) \& }\end{array}$ & $\begin{array}{l}8.0(5.0 \\
12.0)\end{array}$ & $\begin{array}{l}9.0(5.0 \\
15.0)\end{array}$ & $0.10^{\wedge}$ & $0.19(-0.02,0.40)$ & $\begin{array}{l}0.08 \\
\$^{*}\end{array}$ \\
\hline $\begin{array}{l}\text { Hospital Length of Stay } \\
\text { (Days), Median (IQR) \& }\end{array}$ & $\begin{array}{l}14.0 \\
(10.0 \\
23.0)\end{array}$ & $\begin{array}{l}17.0 \\
(13.0 \\
28.0)\end{array}$ & $0.07^{\wedge}$ & $0.15(-0.02-0.32)$ & $\begin{array}{l}0.08 \\
\$^{*}\end{array}$ \\
\hline \multicolumn{6}{|c|}{${ }^{\wedge \wedge}$ Chi-square test is used to calculate the P-value. } \\
\hline \multicolumn{6}{|c|}{ ^ Wilcoxon rank sum test is used to calculate the P-value. } \\
\hline \multicolumn{6}{|c|}{$\begin{array}{l}\text { \$ Propensity score after adjusting for patient's baseline severity scores (i.e., APACHE II, SOFA score, } \\
\text { NUTRIC scores), systemic use of corticosteroids and study centers to calculate hazard ratio and p- } \\
\text { value. }\end{array}$} \\
\hline \multicolumn{6}{|c|}{$\begin{array}{l}\$^{*} \text { propensity score adjusted Generalized linear model is used to calculate beta coefficient (estimates) } \\
\text { and p-value. }\end{array}$} \\
\hline \multicolumn{6}{|c|}{ \&\# Denominator is patients who have respiratory failure requiring MV during ICU stay. } \\
\hline \& Denominator is patients $\mathrm{W}$ & urvived. & & & & \\
\hline
\end{tabular}




\section{Secondary endpoints}

There was no statistically significantly differences in term of MV duration (Beta coefficient $0.10 \mathrm{Cl}=$ $-0.19,0.39 ; p=0.48$ ), ICU LOS (Beta coefficient $0.19 \mathrm{Cl}=-0.02,0.40 ; p=0.08$ ) and hospital LOS (Beta coefficient $0.15 \mathrm{Cl}=-0.02,0.32 ; p=0.08$ ) between the two groups after using propensity score adjustment analysis. (Table 1).

ICU complications during ICU stay were reported in (Table 2). Acute kidney injury occurred in 53 patients (39.9\%) in the zinc group, compared with 41 patients $(31.3 \%)$ in the control group $(\mathrm{OR}(95 \% \mathrm{Cl}): 1.80(1.0$, 2.99), $p=0.02)$. On the other hand, no differences were observed in acute liver injury (OR $(95 \% \mathrm{Cl}): 0.91$ $(0.42,1.98), p=0.81)$, thrombosis/infraction $(\mathrm{OR}(95 \% \mathrm{Cl}): 0.78(0.35,1.70), p=0.52)$ or respiratory failure requiring MV (OR $(95 \% \mathrm{Cl}): 0.77(0.34,1.73), p=0.52)$ as presented in Table 2. The effect of Zinc on COVID-19 inflammatory markers, including CRP and ferritin, was not significant, as shown in Table 3.

Table 2

ICU complication (s) during ICU stay

\begin{tabular}{|c|c|c|c|c|c|}
\hline \multirow[t]{2}{*}{ Outcomes } & \multicolumn{2}{|c|}{ Crude Analysis } & \multirow{2}{*}{$\begin{array}{l}\mathrm{P}- \\
\text { value }\end{array}$} & \multirow{2}{*}{$\begin{array}{l}\text { Odds Ratio (OR) } \\
(95 \% \mathrm{Cl})\end{array}$} & \multirow{2}{*}{$\begin{array}{l}\text { P- } \\
\text { value } \\
\$\end{array}$} \\
\hline & Control & Zinc & & & \\
\hline Acute Kidney Injury (AKI), n(\%) & $\begin{array}{l}41 / 131 \\
(31.3)\end{array}$ & $\begin{array}{l}53 / 133 \\
(39.9)\end{array}$ & $0.15^{\wedge \wedge}$ & $1.80(1.08,3.0)$ & 0.02 \\
\hline Liver Injury, n(\%) & $\begin{array}{l}13 / 131 \\
(9.9)\end{array}$ & $\begin{array}{l}13 / 133 \\
(9.7)\end{array}$ & $0.99^{\wedge \wedge}$ & $0.91(0.42,1.98)$ & 0.81 \\
\hline $\begin{array}{l}\text { Respiratory Failure Requiring } \\
M V, n(\%)\end{array}$ & $\begin{array}{l}23 / 54 \\
(42.6)\end{array}$ & $\begin{array}{l}20 / 57 \\
(35.1)\end{array}$ & $0.42^{\star \star}$ & $0.77(0.34,1.73)$ & 0.52 \\
\hline $\begin{array}{l}\text { Thrombosis/infraction During } \\
\text { ICU, n(\%) }\end{array}$ & $\begin{array}{l}14 / 130 \\
(10.8)\end{array}$ & $\begin{array}{l}12 / 131 \\
(9.2)\end{array}$ & $0.66^{\wedge \wedge}$ & $0.78(0.35,1.70)$ & 0.52 \\
\hline \multicolumn{6}{|c|}{${ }^{\wedge}$ Chi-square /**Fisher Exact test is used to calculate the P-value. } \\
\hline \multicolumn{6}{|c|}{$\$$ propensity score adjusted Logistic regression is used to calculate Odds ratio and p-value. } \\
\hline \multicolumn{6}{|c|}{$\begin{array}{l}{ }^{* \wedge} \text { Multivariable logistic regression is used after adjusting for patient's baseline severity scores, } \\
\text { systemic use of corticosteroids and hospital center to calculate OR and p-value }\end{array}$} \\
\hline \multicolumn{6}{|c|}{$\begin{array}{l}\$ * \text { Denominator of the percentage is non-mechanically ventilated patients with } 24 \text { hours of ICU } \\
\text { admission }\end{array}$} \\
\hline
\end{tabular}


Table 3

COVID-19 Inflammatory Surrogate Markers

\begin{tabular}{|llll|}
\hline Surrogate markers & $\begin{array}{l}\text { Control } \\
(\mathbf{N}=133)\end{array}$ & $\begin{array}{l}\text { Zinc } \\
(\mathbf{N}=133)\end{array}$ & $\begin{array}{l}\text { P- } \\
\text { value }\end{array}$ \\
\hline CRP Baseline (mg/l), Median (IQR) & $149.0(84.00,238.00)$ & $136.0(73.00,201.00)$ & $0.18^{\wedge}$ \\
\hline CRP Follow-up (mg/l), Median (IQR) & $150.0(76.00,270.00)$ & $153.0(74.00,256.00)$ & $0.41^{\wedge}$ \\
\hline Ferritin Baseline (ug/l), Median (IQR) & $712.5(338.40$, & $951.9(527.90$, & $0.07^{\wedge}$ \\
& $1981.00)$ & $2132.65)$ & \\
\hline $\begin{array}{l}\text { Ferritin Follow-up (ug/l), Median } \\
\text { (IQR) }\end{array}$ & $733.1(335.30$, & $973.8(600.10$, & $0.01^{\wedge}$ \\
\hline
\end{tabular}

\section{Discussion}

In this two-center, retrospective, propensity score matching study, zinc used as adjunctive therapy was associated with lower in-hospital and 30-day mortality in critically ill patients with COVID-19; but did not reach a statistically significant difference (HR 0.67; $p$-value $=0.05$ and HR 0.65; $p$-value $=0.05)$. Moreover, a previous retrospective study has shown that the use of zinc in combination with hydroxychloroquine and azithromycin in hospitalized patients with COVID-19 reduces mortality. ICU admission and MV need compared with patients who did not receive zinc; however, mortality benefits were not observed after excluding ICU patients [22].

A subgroup analysis of severe and critically ill patients with COVID-19 found that the use of zinc was not associated with a significant reduction in-hospital mortality[23]. Additionally, a multi-center randomized controlled (RCT) study reported that the use of zinc combined with hydroxychloroquine did not affect the overall mortality in patients with COVID-19 compared to the patients who did not receive zinc[24]

A systematic review of four randomized trials conducted in non-COVID-19 critically ill patients found that zinc supplementation was not associated with a significant reduction in mortality or ICU length of stay [19]. While in this study, the duration of MV, ICU LOS, and hospital stay was not significantly reduced in the zinc group compared to the control group. These results are consistent with previous retrospective and RCT studies showing that the concomitant use of zinc with hydroxychloroquine did not affect the ICU, LOS, hospital LOS, duration of MV[22, 24]. It is worth mentioning that most of these studies included patients with mild, moderate, and severe COVID-19 [22, 24]. Moreover, zinc supplementation has been shown to reduce cytokine levels in rhinovirus (RSV) infections [27]. However, we did not find that zinc affects COVID-19 disease progression evident by surrogate markers. In pregnant patients infected with COVID-19, Zinc to copper ratio correlated with inflammatory and acute phase markers, including IL-6 and CRP [28].

In terms of the complications during ICU stay, zinc use was associated with a higher odds of acute kidney injury. Oppositely, zinc was thought to reduce renal injury incidence via its antioxidant effect in rats [25]; 
our study may contradict these pre-clinical data. The exact mechanism and explanation for the increased AKI risk observed in our cohort are unknown. However, other risk factors for AKI were not assessed, such as the concomitant use of other nephrotoxic medications. These findings worth further investigation about the precise impact of zinc supplementation on renal function in critically ill COVID-19 patients.

The current National Institute of Health $(\mathrm{NIH})$ recommends against zinc supplementation to treat or prevent COVID-19[29]. This recommendation was based on the lack of clinical data to support its role in COVID-19 and its potential harm from long-term zinc administration. When combined with anti-viral therapy, the timing of zinc supplementation and its beneficial effect are essential factors determining its role in COVID-19 disease progression. Early administration of zinc with anti-viral therapy in COVID-19 patients may potentiate their anti-viral effect as it did in patients with the common cold [27, 30]. Previous reports, including out-patients with COVID-19, administered zinc early after diagnosis [18, 31]. However, the benefit of early versus late zinc initiation in COVID-19 patients is still unclear.

Currently, the available evidence about the use of zinc in critically ill patients is limited. Many of the previous reports investigated zinc use in either non-COVID-19 or non-critically ill patients. As we are writing this manuscript, there is an ongoing double-blinded RCT study investigating the use of high-dose zinc in critically ill patients with SARS-COV2[32]. Compared to the published data, this study is one of the few studies that assessed the use of zinc in critically ill patients with COVID-19 with a propensity-scorematched group of patients. Nonetheless, it still has several limitations; such as the observational nature, small sample size, and the possibility of residual confounding. Given these limitations, the study's findings should not be used to guide clinical practice but to support the need for future randomized clinical trials to investigate the potential impact of zinc supplementation in critically ill COVID-19 patients.

\section{Conclusion}

In critically ill patients with COVID-19, zinc as adjunctive therapy may have survival benefit; however, was not statistically significant. In contrast, the use of zinc was linked to an increased risk of AKI development during ICU stay. Further randomized clinical and interventional studies are needed to confirm and generalize our findings.

\section{Abbreviation}

Intensive care units (ICUs), Coronavirus disease (COVID-19), Mechanical ventilation (MV), Length of Stay (LOS).

\section{Declarations}

\section{Acknowledgments}

We acknowledge Dr. Hakeam A. Hakeam for his support during the study execution. 


\section{Author contributions}

KS and OJ equally contributed to the conception and design of the research; $A S, G K, A K, S A, R K, R V$ and $A A$ contributed to the design of the research; $K S, O J, A S, G K, A K, S A, R K, R V, A A B, R G$ and $A A$ contributed to the acquisition and analysis of the data; KS, OJ, AS, GK contributed to the interpretation of the data; $\mathrm{KS}, \mathrm{OJ}, \mathrm{AS}, \mathrm{SA}, \mathrm{AK}, \mathrm{RK}, \mathrm{AA}, \mathrm{AAB}, \mathrm{RG}$ and RV drafted the manuscript. All authors critically revised the manuscript, agree to be fully accountable for ensuring the integrity and accuracy of the work, and read and approved the final manuscript.

\section{Funding}

None.

\section{Availability of data and material}

The datasets used and/or analyzed during the current study are available from corresponding author on reasonable request.

\section{Ethics approval and consent to participate}

The study was approved in November 19th, 2020 by King Abdullah International Medical Research Center Institutional Review Board, Riyadh, Saudi Arabia (Reference No: RC20/589/R).

Participants' confidentiality was strictly observed throughout the study using the anonymous unique serial number for each subject and restricting data only to the investigators. Informed consent was not required due to the research's method as per the policy of the governmental and local research center.

\section{Consent for publication}

Not applicable.

\section{Competing interests}

No author has a conflict of interest in this study.

\section{References}

1. Huang C, Wang Y, Li X, Ren L, Zhao J, Hu Y, et al. Clinical features of patients infected with 2019 novel coronavirus in Wuhan, China. The Lancet. Lancet Publishing Group; 2020;395:497-506.

2. Wang D, Hu B, Hu C, Zhu F, Liu X, Zhang J, et al. Clinical Characteristics of 138 Hospitalized Patients with 2019 Novel Coronavirus-Infected Pneumonia in Wuhan, China. JAMA - Journal of the American Medical Association. American Medical Association; 2020;323:1061-9.

3. Coomes EA, Haghbayan H. Interleukin-6 in COVID-19: A systematic review and meta-analysis. medRxiv. medRxiv; 2020. 
4. al Sulaiman KA, Aljuhani O, Eljaaly K, Alharbi AA, al Shabasy AM, Alsaeedi AS, et al. Clinical features and outcomes of critically ill patients with coronavirus disease 2019 (COVID-19): A multicenter cohort study. International Journal of Infectious Diseases. Elsevier B.V.; 2021;105:180-7.

5. Zumla A, Hui DS, Azhar El, Memish ZA, Maeurer M. Reducing mortality from 2019-nCoV: hostdirected therapies should be an option. The Lancet. Lancet Publishing Group; 2020. p. e35-6.

6. Alhazzani W, Evans L, Alshamsi F, Møller MH, Ostermann M, Prescott HC, et al. Surviving Sepsis Campaign Guidelines on the Management of Adults with Coronavirus Disease 2019 (COVID-19) in the ICU: First Update. Critical Care Medicine. Lippincott Williams and Wilkins; 2021;E219-34.

7. The RECOVERY Collaborative Group. Dexamethasone in Hospitalized Patients with Covid-19. New England Journal of Medicine [Internet]. 2021;384:693-704. Available from: http://www.nejm.org/doi/10.1056/NEJMoa2021436

8. Gupta S, Wang W, Hayek SS, Chan L, Mathews KS, Melamed ML, et al. Association between Early Treatment with Tocilizumab and Mortality among Critically III Patients with COVID-19. JAMA Internal Medicine. American Medical Association; 2021;181:41-51.

9. Veiga VC, Prats JAGG, Farias DLC, Rosa RG, Dourado LK, Zampieri FG, et al. Effect of tocilizumab on clinical outcomes at 15 days in patients with severe or critical coronavirus disease 2019: Randomised controlled trial. The BMJ. BMJ Publishing Group; 2021;372.

10. Aleissa MM, Silverman EA, Paredes Acosta LM, Nutt CT, Richterman A, Marty FM. New perspectives on antimicrobial agents: Remdesivir treatment for COVID-19. Antimicrobial Agents and Chemotherapy. American Society for Microbiology; 2021;65.

11. Shakoor H, Feehan J, al Dhaheri AS, Ali HI, Platat C, Ismail LC, et al. Immune-boosting role of vitamins D, C, E, zinc, selenium and omega-3 fatty acids: Could they help against COVID-19? Maturitas. 2021;143.

12. Mullin GE, Limektkai B, Wang L, Hanaway P, Marks L, Giovannucci E. Dietary Supplements for COVID19. 2021.

13. Barnard DL, Wong M-H, Bailey K, Day CW, Sidwell RW, Hickok SS, et al. Effect of oral gavage treatment with ZnAL42 and other metallo-ion formulations on influenza A H5N1 and H1N1 virus infections in mice. Antiviral Chemistry \& Chemotherapy.

14. Read SA, Obeid S, Ahlenstiel C, Ahlenstiel G. The Role of Zinc in Antiviral Immunity. Advances in Nutrition. Oxford University Press; 2019. p. 696-710.

15. te Velthuis AJW, van den Worml SHE, Sims AC, Baric RS, Snijder EJ, van Hemert MJ. Zn2+ inhibits coronavirus and arterivirus RNA polymerase activity in vitro and zinc ionophores block the replication of these viruses in cell culture. PLoS Pathogens. 2010;6.

16. PORMOHAMMAD A, MONYCH NK, TURNER RJ, PORMOHAMMAD A. Zinc and SARS-CoV-2: A molecular modeling study of Zn interactions with RNA-dependent RNA-polymerase and 3C-like proteinase enzymes. International Journal of Molecular Medicine. Spandidos Publications; 2021;47:326-34. 
17. Kumar A, Kubota Y, Chernov M, Kasuya H. Potential role of zinc supplementation in prophylaxis and treatment of COVID-19. Medical Hypotheses. Churchill Livingstone; 2020;144.

18. Derwand R, Scholz M, Zelenko V. COVID-19 outpatients: early risk-stratified treatment with zinc plus low-dose hydroxychloroquine and azithromycin: a retrospective case series study. International Journal of Antimicrobial Agents. Elsevier B.V.; 2020;56.

19. Heyland DK, Jones N, Cvijanovich NZ, Wong H. Review: Zinc supplementation in critically ill patients: A key pharmaconutrient? Journal of Parenteral and Enteral Nutrition. 2008. p. 509-19.

20. Lin CY, Chen YC. Acute kidney injury classification: AKIN and RIFLE criteria in critical patients. World J Crit Care Med. 2012;1(2):40-45. Published 2012 Apr 4. doi:10.5492/wjccm.v1.i2.40

21. ICD - ICD-10-CM - International Classification of Diseases, Tenth Revision, Clinical Modification. 2021.

22. Carlucci PM, Ahuja T, Petrilli C, Rajagopalan H, Jones S, Rahimian J. Hydroxychloroquine and azithromycin plus zinc vs hydroxychloroquine and azithromycin alone: outcomes in hospitalized COVID-19 patients. medRxiv. medRxiv; 2020.

23. Yao JS, Paguio JA, Dee EC, Tan HC, Moulick A, Milazzo C, et al. The Minimal Effect of Zinc on the Survival of Hospitalized Patients With COVID-19: An Observational Study. Chest. Elsevier Inc.; 2021;159:108-11.

24. Abd-Elsalam S, Soliman S, Esmail ES, Khalaf M, Mostafa EF, Medhat MA, et al. Do Zinc Supplements Enhance the Clinical Efficacy of Hydroxychloroquine?: a Randomized, Multicenter Trial. Biological Trace Element Research. Humana Press Inc.; 2020;

25. Salehipour M, Monabbati A, Ensafdaran MR, Adib A, Babaei AH. The effect of zinc on healing of renal damage in rats. Journal of Nephropathology. Society of Diabetic Nephropathy Prevention; 2017;6:157-62.

26. King JC, Shames DM, Woodhouse LR. Zinc Homeostasis in Humans. The Journal of Nutrition. 2000;130.

27. Prasad AS, Fitzgerald JT, Beck FWJ, Chandrasekar PH. Annals of Internal Medicine Duration of Symptoms and Plasma Cytokine Leveis in Patients with the Common Cold Treated with Zinc Acetate A Randomized, Double-Blind, Placebo-Controlled Trial. 2000.

28. Anuk AT, Polat N, Akdas S, Erol SA, Tanacan A, Biriken D, et al. The Relation Between Trace Element Status (Zinc, Copper, Magnesium) and Clinical Outcomes in COVID-19 Infection During Pregnancy. Biological Trace Element Research. Humana Press Inc.; 2020;

29. National Insitute of Health. Zinc: COVID-19 Treatment Guideline. https://www.covid19treatmentguidelines.nih.gov/supplements/zinc/. 2021.

30. Mossad SB, Macknin ML, Medendorp S v, Mason P. Zinc Gluconate Lozenges for Treating the Common Cold A Randomized, Double-Blind, Placebo-Controlled Study. Annals of Internal Medicine Number. 1996.

31. Thomas S, Patel D, Bittel B, Wolski K, Wang Q, Kumar A, et al. Effect of High-Dose Zinc and Ascorbic Acid Supplementation vs Usual Care on Symptom Length and Reduction among Ambulatory 
Patients with SARS-CoV-2 Infection: The COVID A to Z Randomized Clinical Trial. JAMA Network Open. American Medical Association; 2021;4.

32. Perera M, el Khoury J, Chinni V, Bolton D, Qu L, Johnson P, et al. Randomised controlled trial for highdose intravenous zinc as adjunctive therapy in SARS-CoV- 2 (COVID-19) positive critically ill patients: Trial protocol. BMJ Open. BMJ Publishing Group; 2020;10.

\section{Figures}

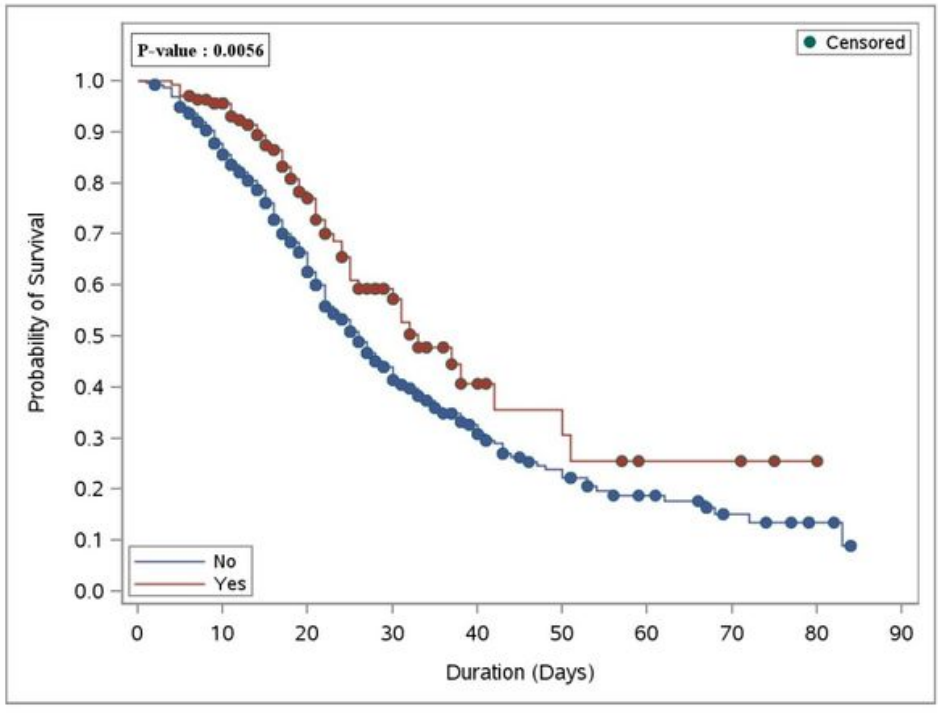

$1 a$

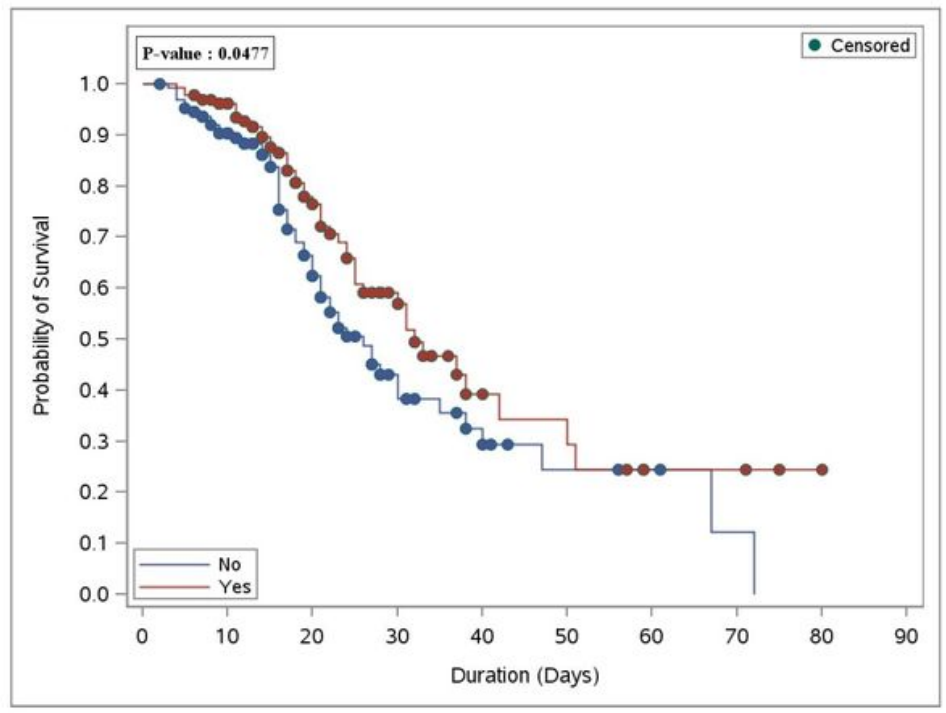

$1 b$

\section{Figure 1}

1a: Overall survival plot during hospital stay (Before PS matching). Overall survival plot during hospital stay comparing patient who received zinc as adjunctive therapy versus control group - Before PS matching 1b: Overall survival plot during hospital stay (After PS matching). Overall survival plot during hospital stay comparing patient who received zinc as adjunctive therapy versus control group - After PS matching

\section{Supplementary Files}

This is a list of supplementary files associated with this preprint. Click to download.

- Additionalfile1DemographyandBaselinecharacteristics.docx

- Additionalfile2Coexistingillness.docx 